\title{
An SD Analysis of China's Foreign Exchange Reserves Environment Effect
}

\author{
Juan Wang, Dimitrios Tsagdis, Haibo Chen \\ School of Finance \& Economics, Jiangsu University, zhenjiang, 212013, China \\ Hull University Business School, Filey Road, YO11 3AZ, UK
}

\begin{abstract}
The environment effect of China's tremendous foreign exchange reserves is striking in recent years. Centring on key indexes, a system dynamics study is made using software VENSIM. First, functions among variables, such as foreign exchange reserves, energy consumption, energy production, energy import, pollution control investment, export, FDI, and import, are determined in line with system dynamics principles by using software EVIEWS, EXCEL, SPSS \& HLM. Next, model validity check including visual inspection, running inspection and history test is made which shows a good fitness between the model constructed and the reality and hence can be used in forecast and simulation. Finally, suggestions are proposed.
\end{abstract}

Keywords-environment effect; system dynamics (SD); foreign exchange reserves (FER); simulation; forecast

\section{INTRODUCTION}

Accompanying the formation of huge foreign exchange reserves, negative effects are becoming increasingly remarkable nowadays: equivalent loss of domestic resources, severe pollution, aggravated imbalance, FER shrinkage, sustained inflation, trade frictions, and poor innovation. In particular, news report on safety accidents, pneumoconiosis, excessive amounts of lead in the blood, cancer villages, and chromium poisoning \& cadmium rice appeared frequently on the media. Literature show that export-oriented economic growth brought pollution and resources runaway ${ }^{[1]-[6]}$. This paper targets at safeguarding China's sustainable economic development while curbing its negative effect.

\section{SD MODEL CONSTRUCTION AND THE VALIDITY TEST OF CHINA'S FER ENVIRONMENT EFFECT}

System dynamics (SD) is suitable for analysis of complex social \& economic problems through dynamic representation of the intriguing relationship between interacting $\&$ inter-constraining variables.

\section{A. Variable Selection \& Cause-effect Diagram}

Centering on FER and GDP indexes, sub-systems of environment effect, FER formation \& discharge, inflation effect, and technological innovation effect are established. Variables in FER formation \& discharge sub-system include FER, FDI, export, exchange rate, import, ODI、MNC profit, disposable income per capita, globalization index, economic incentive mechanism index; variables in environment effect sub-system include energy consumption, energy production, energy import, resources carrying capacity, pollution, pollution control investment; variables in inflation subsystem include GDP, money supply, investment demand, interest rate, CPI; variables in technological innovation subsystem which affect FER formation \& discharge include research \& development (RD) expenditure, R\&D percentage in GDP, patent application acceptance number, new product sales revenue, high-tech product export, etc..

The cause and effect relationship diagram of the FER dynamic system is drawn combining micro \& macro analysis as in figure 1 .

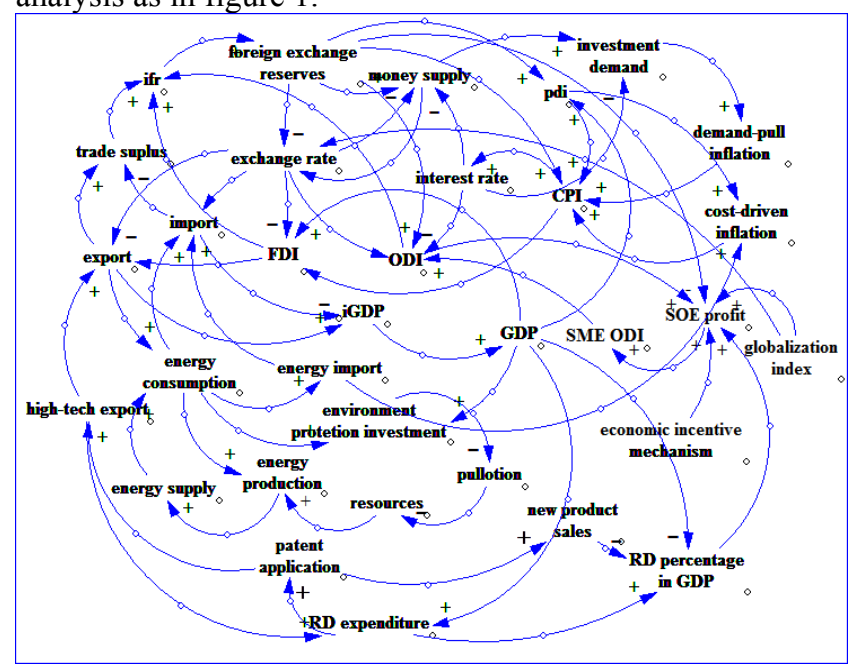

Figure 1. Cause \& effect diagram of FER dynamic system

The cause \& effect diagram of FER dynamic system displays several key feedback loops:

(1) FER $\rightarrow \rightarrow$ exchange rate $\rightarrow \rightarrow \mathrm{FDI} \rightarrow \rightarrow$ export $\rightarrow \rightarrow$ trade balance $\rightarrow \rightarrow$ FER

(2) FER $\rightarrow \rightarrow$ exchange rate $\rightarrow \rightarrow$ import $\rightarrow \rightarrow$ trade balance $\rightarrow \rightarrow$ FER

(3) FER $\rightarrow \rightarrow$ exchange rate $\rightarrow \rightarrow$ import $\rightarrow \rightarrow$ GDP $\rightarrow \rightarrow$ $\mathrm{R} \& \mathrm{D}$ percentage $\rightarrow \longrightarrow \mathrm{SOE}$ profits $\rightarrow \longrightarrow \mathrm{SME}$ profits $\rightarrow \rightarrow \mathrm{ODI} \rightarrow \rightarrow$ FER

(4) FER $\rightarrow \rightarrow$ exchange rate $\rightarrow \rightarrow$ import $\rightarrow \mathrm{GDP} \rightarrow \longrightarrow \mathrm{R} \& \mathrm{D} \quad$ expenditure $\rightarrow \rightarrow$ patent application acceptance number $\rightarrow \longrightarrow$ high-tech export $\rightarrow \longrightarrow$ total export $\rightarrow \rightarrow$ trade balance $\rightarrow \rightarrow$ FER

(5) FER $\rightarrow \rightarrow$ exchange rate $\rightarrow \rightarrow$ import $\rightarrow \rightarrow$ GDP $\rightarrow \longrightarrow$ disposable income per capita $\rightarrow \rightarrow$ cost-push inflation $\rightarrow \rightarrow$ inflation $\rightarrow \rightarrow \mathrm{FDI} \rightarrow \rightarrow$ export $\rightarrow \rightarrow$ trade balance $\rightarrow \rightarrow$ FER 
(6) GDP $\rightarrow$ pollution control investment $\rightarrow \rightarrow$ pollution caused by energy consumption $\rightarrow \rightarrow$ resources bearing capacity $\rightarrow \rightarrow$ total energy production $\rightarrow \longrightarrow$ total energy supply $\rightarrow \rightarrow$ total energy consumption $\rightarrow \rightarrow$ energy import $\rightarrow \rightarrow$ import $\rightarrow \rightarrow$ GDP incremental $\rightarrow \rightarrow$ GDP

(7) $\mathrm{GDP} \rightarrow \longrightarrow \mathrm{FDI} \rightarrow \longrightarrow$ export $\rightarrow \rightarrow \mathrm{GDP}$ incremental $\rightarrow \rightarrow \mathrm{GDP}$

(8) $\quad$ GDP $\rightarrow \rightarrow$ DI $\rightarrow \rightarrow$ cost-push inflation $\rightarrow \rightarrow$ inflation $\rightarrow \rightarrow \mathrm{FDI} \rightarrow \rightarrow$ export $\rightarrow \rightarrow$ GDP incremental $\rightarrow$ GDP

(9) GDP $\rightarrow \rightarrow$ DI $\rightarrow \rightarrow$ inflation $\rightarrow \rightarrow$ interest rate $\rightarrow \longrightarrow$ money supply $\rightarrow \rightarrow$ exchange rate $\rightarrow$ import $\rightarrow \rightarrow$ GDP incremental $\rightarrow \rightarrow$ GDP

(10) Inflation expectation $\rightarrow \rightarrow$ interest rate $\rightarrow$ investment demand $\rightarrow \rightarrow$ demand-pull inflation $\rightarrow \rightarrow$ inflation expectation

(11) Inflation $\rightarrow$ interest $\quad$ rate $\rightarrow \rightarrow$ money supply $\rightarrow \rightarrow$ exchange rate $\rightarrow \rightarrow \mathrm{ODI} \rightarrow \rightarrow$ FER $\rightarrow \rightarrow$ inflation

(12) Inflation $\rightarrow \rightarrow$ interest rate $\rightarrow$ money supply $\rightarrow \rightarrow$ exchange $\quad$ rate $\rightarrow \longrightarrow \quad$ export $\rightarrow \rightarrow$ energy consumption demand $\rightarrow \rightarrow$ energy import demand $\rightarrow \longrightarrow$ cost-push inflation $\rightarrow \rightarrow$ inflation

The cause and effect relationship of the FER dynamic system involving key variables is as follows

Huge FER causes increase of RMB value which attracts more inflow of FDI. Since most exports were generated by foreign funded enterprises, trade surplus further increases FER. Meanwhile, appreciation of RMB value promotes import which helps decrease FER. Trade surplus increases GDP, the increases of disposable income per capita may cause cost-push inflation. Inflation increases interest rate which curbs money supply.

Other things being equal, with the increase of GDP more expenditure can be spend on pollution control which in turn help decrease pollution caused by energy consumption. The decrease of pollution is beneficial to resources bearing capacity. The more energy production, the more energy supply can be consumed and less energy import is required.

Other things being equal, with the increase of GDP more expenditure can be spend on $R \& D$. With the increase of R\&D expenditure, MNC profits increase which promotes overseas investment. While ODI increase helps decrease FER.

\section{B. Functions Among Variables \& Synthetic Simulation Diagram}

In consideration of sharp increase after China entrance into WTO in 2001, variable data are collected from year 2002 on. Data sources are China Statistical Yearbook (2001 2013) and International Statistical Yearbook (2008 2013).

Value assignment methods include: (1) Initial values of level variables are assigned, and initial year is 2002. (2) Functions of auxiliary variables are set by methods such as multiple regression, dummy variable regression, and hierarchical lineal regression, using software such as SPSS, EVIEWS, EXCEL, and HLM. (3) Some constant variables are assigned mean values. Final equations among variables are as follows.
(1) FER= INTEG (FER incremental, 2864.07), Units: 0.1 billion dollars;

(2) FER incremental = export +FDI-ODI- import, Units: 0.1 billion dollars;

(3) Trade balance $=$ export - import, Units: 0.1 billion dollars;

(4) Export $=-2477.05^{*}$ exchange rate $23693.3 * \mathrm{LN}(\mathrm{FDI})+23272.4 * \mathrm{LN}($ high-tech products export), Units: 0.1 billion dollars;

$$
(-3.378512 * * *) \quad(-2.046674 *) \quad(2.582249 * *)
$$

$R^{2}=0.950371$, Durbin-Watson stat $=1.932850$

(5) import $=637.266^{*}$ total energy consumption 991.964* exchange rate, Units: 0.1 billion dollars; $(14.64145 * * *) \quad(-6.164175 * * *)$

$R^{2}=0.942947$, Durbin-Watson stat $=1.122441$

(6) $\mathrm{FDI}=-152.334 *$ exchange rate $+0.00412188^{*} \mathrm{GDP}+$ 17.3766*CPI, Units: 0.1 billion dollars;(-3.962069***) $(2.866243 * *) \quad(5.223626 * * * *)$

$R^{2}=0.983690$, Durbin-Watson stat $=1.698504$

(7) $\mathrm{ODI}=3278.59$ - 390.084* exchange rate, Units: 0.1 billion dollars;

$(-26.50129 * * * *) R^{2}=0.987347, \quad$ DW stat $=2.311205$

(8) Exchange rate $=11.1676-0.300012 *$ LN ( FER) $3.63185 \mathrm{e}-005 * \mathrm{M} 1$,

Units: $¥ / \$$;

$$
(-1.704717 *) \quad(-3.528747 * * *)
$$

$R^{2}=0.950605, \quad$ Prob $($ F-statistic $)=0.000006$

(9) $\mathrm{M} 1=2903.73+1.28519 *$ FER,Units: 0.1 billion dollars;

$\left(2.283108^{* *}\right)(20.09846 * * * *) ; R^{2}=0.978205$, DW stat $=0.491554$

(10) $\quad \mathrm{pdi}=\mathrm{IF} \quad$ THEN $\quad$ ELSE(Time $>=2007$, $0.49298+0.54325 *$ FER, $0.35057+0.90765 *$ FER), Units: $¥$, $R^{2}=0.969970$

\begin{tabular}{|c|c|c|c|}
\hline variable & coefficient & t-statistics & P-value \\
\hline C & 0.350570 & 8.374930 & 0.0000 \\
\hline FR & 0.907649 & 8.709810 & 0.0000 \\
\hline DV*FR & -0.364399 & -2.788792 & 0.0121 \\
\hline
\end{tabular}

This equation is a result from FER effects empirical analysis.

(11) $\mathrm{CPI}=119.274+0.00161855 * \mathrm{FER}-0.00300953 *$ pdi, Units: Dmnl

$(25.21413 * * * *) \quad(2.657813 * * *) \quad(-2.974924 * * *)$

R-squared $=0.7629, \quad$ Prob(F-statistic $)=0.00007$, DW stat $=2.3140$

(12) Time is an inherent variable of VENSIM

(13) Globalization index= 59.37, Units: Dmnl

(14) Economic incentive mechanism index $=3.79$,Units: Dmnl

(15) Igdp= export - import, Units: 0.1 billion dollars;

(16) GDP= INTEG ( igdp, 14538.2), Units: 0.1 billion dollars;

(17) Total energy consumption $=14.2247+$ $0.00112301 *$ export, Units: 0.1 billion ton standard coal, $(14.62784 * * * *)(14.54111 * * * *)$ 
R-squared $=0.959173, \operatorname{Prob}($ F-statistic $)=0.0000, \mathrm{DW}=$ 1.646101

(18) Energy production $=2.736820+0.7609600 *$ total energy consumption $+0.0020971^{*}$ pollution control investment, Units: 0.1 billion ton standard coal

$(4.262015 * * *) \quad(21.96384 * * * *) \quad(3.838769 * * *)$

R-squared $=0.998370, \quad$ Prob(F-statistic $)=0.000000$

(19) Pollution control investment $=-114.29+$ $5.9398 * \mathrm{LN}$ (total energy consumption) $+0.01751 * \mathrm{GDP}$, Units: 0.1 billion dollars;

$$
(-0.184750)(0.027534) \quad(7.220173 * * * *)
$$

R-squared $=0.971971, \operatorname{Prob}(\mathrm{F}$-statistic $)=0.000001, \mathrm{DW}=$ 2.419021

(20) New product sales revenue $=\quad-978.535+$ 94.8434* patent application

$$
(-2.058440 * *) \quad(22.21588 * * * *)
$$

R-squared $=0.986015$, Durbin-Watson stat $=2.066594$

(21) Patent application $=20.092 * \operatorname{EXP}(0.206 *$ (Time2001)), Units: 10 thousand pieces, $\quad \mathrm{y}=$ $20.092 \mathrm{e} 0.206 \mathrm{x}, \mathrm{R}^{2}=0.9963$

(22) High-tech products export $=4.9361 *($ Time2001)*(Time-2001)+480.85*(Time-2001) +1813.3, Units: 0.1 billion dollars;

$$
\mathrm{y}=4.9361 \mathrm{x} 2+480.85 \mathrm{x}+1813.3, \mathrm{R}^{2}=0.959
$$

(23) $\mathrm{R} \& \mathrm{D}$ expenditure $=0.0193507 *$ GDP $-0.101762 *$ high-tech export $+0.0347615^{*}$ new product sales revenue, Units: 0.1 billion dollars;

$$
(2.730391 * *)\left(-2.270745^{* *}\right) \quad(1.793189 *),
$$

R-squared $=0.996197$, Durbin-Watson stat $=2.987215$

(24) $R \& D$ expenditure percentage in GDP $=R \& D$ expenditure /GDP, Units: **undefined**

(25) $\mathrm{MNC}$ profits $=4664.95-3682.48 *$ EIR index $+379.473^{*}$ R\&D expenditure percentage in GDP $0.259544 *$ FER +6.98833*ODI+567.262* globalization index -27.5987 , Units: 0.1 billion dollars;

This equation is a result of FER discharge empirical analysis.

The synthetic simulation diagram of FER dynamic system is shown in figure 2 .

\section{Model Validity Check}

\section{1) Visual Test}

A lot of literatures are consulted in the construction of this model, which assured the logic conformity of the model to reality. In addition, the fitness, T-statistics, significance and DW value of regressions further guaranteed the soundness of equations.

\section{2) Running Test}

Running test is done with different steps, i.e., a quarter $(\mathrm{DT}=0.25)$, half a year $(\mathrm{DT}=0.5)$, and one year $(\mathrm{DT}=1)$, as shown in figure.3. It can be seen from figure. 3 that with different steps, main variables show a slight change, which indicate stability of the system.

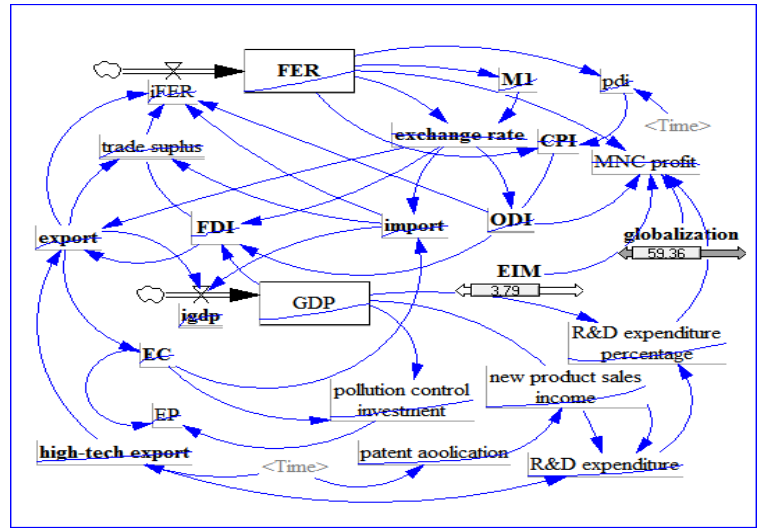

Figure 2. Synthetic simulation diagram of FER dynamic system
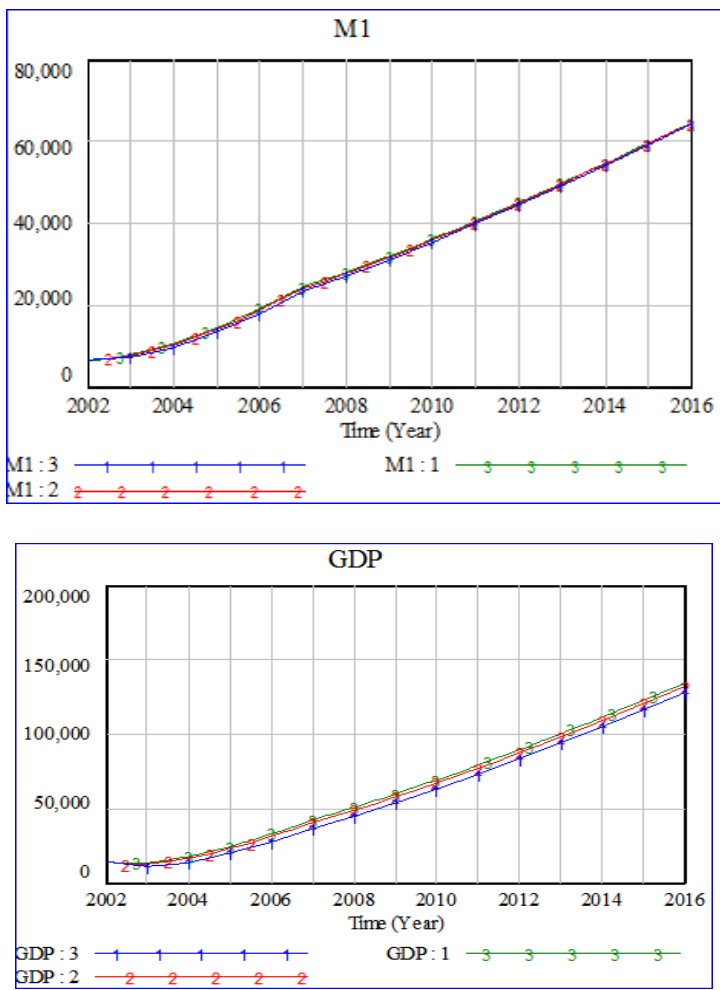

Figure 3. Running test of main variables at different steps

\section{3) History Test}

History test of the model is to check the ration of difference between the simulation value and real value to the real value. Take 8 main variables, i.e., energy consumption, energy production, FER, exchange rate, M1, CPI, patent application acceptance, new product sales revenue, from the flow chart as an example, their relative error check result is shown in TableI. 
TABLE I. RELATIVE ERRORS OF 12 MAIN VARIABLES

\begin{tabular}{|c|c|c|c|c|c|c|}
\hline \multirow[t]{2}{*}{ yea } & \multicolumn{3}{|c|}{ FER( 0.1 billion dollars $)$} & \multicolumn{3}{|c|}{ M1(0.1 billion dollars) } \\
\hline & Real & Simulation value & error & Real value & SV & erro \\
\hline 20 & 2864.07 & 2,864 & 0 & 8563.705 & 6.584 & - \\
\hline 20 & 4092.6 & 3,474 & -0.151 & 10162.93 & 7,369 & - \\
\hline 20 & 6145 & 5,421 & -0.110 & 11595.02 & 9,871 & - \\
\hline 20 & 8215.1 & 8,249 & 0.004 & 13096.04 & 13,506 & 0.03 \\
\hline 20 & 10684.9 & 11,794 & 0.103 & 15810.12 & 18,062 & 0.14 \\
\hline 20 & 15282.5 & 15,969 & 0.044 & 20063.14 & 23,427 & 0.16 \\
\hline 20 & 19460.3 & 18,813 & -0.033 & 23933.01 & 27.082 & 0.13 \\
\hline 20 & 23991.5 & 21,935 & -0.085 & 32206.34 & 31,094 & - \\
\hline 20 & 28473.3 & 25,269 & -0.112 & 39385.7 & 35,379 & - \\
\hline 20 & 31811 & 28,768 & -0.095 & 44876.4 & 39,877 & - \\
\hline 20 & 33116 & 32,398 & -0.021 & 48898.69 & 44,542 & - \\
\hline
\end{tabular}

\begin{tabular}{|c|c|c|c|c|c|c|}
\hline \multirow[t]{2}{*}{$\mathrm{y}$} & \multicolumn{3}{|c|}{ exchange rate } & \multicolumn{3}{|c|}{ CPI } \\
\hline & Real value & SV & error & Real value & SV & error \\
\hline 2 & 8.28 & 8.54 & 0.031 & 99.2 & 116.08 & 0.170 \\
\hline 2 & 8.28 & 8.453 & 0.021 & 101.2 & 115.4 & 0.140 \\
\hline 2 & 8.28 & 8.229 & -0.005 & 103.9 & 113.23 & 0.089 \\
\hline 2 & 8.19 & 7.971 & -0.026 & 101.8 & 110.09 & 0.081 \\
\hline 2 & 7.97 & 7.698 & -0.034 & 101.5 & 106.14 & 0.045 \\
\hline 2 & 7.60 & 7.413 & -0.025 & 104.8 & 119.01 & 0.135 \\
\hline 2 & 6.95 & 7.231 & 0.041 & 105.9 & 118.96 & 0.123 \\
\hline 2 & 6.83 & 7.039 & 0.030 & 99.3 & 118.91 & 0.197 \\
\hline 2 & 6.77 & 6.841 & 0.010 & 103.3 & 118.85 & 0.150 \\
\hline 2 & 6.46 & 6.639 & 0.027 & 105.4 & 118.8 & 0.127 \\
\hline 2 & 6.31 & 6.433 & 0.019 & 102.6 & 118.74 & 0.157 \\
\hline
\end{tabular}

\begin{tabular}{|c|c|c|c|c|c|c|}
\hline \multirow{2}{*}{ year } & \multicolumn{3}{|c|}{ energy consumption( 0.1 btsc $)$} & \multicolumn{3}{|c|}{ energy production ( 0.1 billion tons of standard coal) } \\
\hline & Real value & SV & error & Real value & SV & error \\
\hline 200 & 15.9431 & 15.7 & -0.015 & 15.0656 & 15.08 & 0.000 \\
\hline 200 & 18.3792 & 21.5 & 0.169 & 17.1906 & 18.21 & 0.059 \\
\hline 200 & 21.3456 & 26.17 & 0.226 & 19.6648 & 21.9 & 0.113 \\
\hline 200 & 23.5997 & 30.38 & 0.287 & 21.6219 & 25.59 & 0.183 \\
\hline 200 & 25.8676 & 34.33 & 0.327 & 23.2167 & 29.1 & 0.253 \\
\hline 200 & 28.0508 & 29.43 & 0.049 & 24.7279 & 26.34 & 0.065 \\
\hline 200 & 29.1448 & 31.28 & 0.073 & 26.0552 & 28.07 & 0.077 \\
\hline 200 & 30.6647 & 32.92 & 0.073 & 27.4619 & 29.61 & 0.078 \\
\hline 201 & 32.4939 & 34.38 & 0.058 & 29.6916 & 31 & 0.044 \\
\hline 201 & 34.8002 & 35.72 & 0.026 & 31.7987 & 32.27 & 0.014 \\
\hline 201 & 36.1732 & 36.96 & 0.021 & 33.1848 & 33.44 & 0.007 \\
\hline
\end{tabular}

\begin{tabular}{|c|c|c|c|c|c|c|}
\hline \multirow[t]{2}{*}{ ye } & \multicolumn{3}{|c|}{ patent application acceptance( 10 thousand pieces) } & \multicolumn{3}{|c|}{ new product sales revenue ( 0.1 billion $\$$ ) } \\
\hline & Real value & SV & error & Real value & SV & error \\
\hline 20 & 35.3807 & 37.27 & 0.053 & 2755.725 & 2556 & -0.072 \\
\hline 20 & 47.6264 & 45.8 & -0.038 & 2941.647 & 3365 & 0.143 \\
\hline 20 & 57.3178 & 56.27 & -0.018 & 3917.912 & 4359 & 0.112 \\
\hline 20 & 69.3917 & 69.15 & -0.003 & 5388.765 & 5580 & 0.035 \\
\hline 20 & 83 & 84.97 & 0.025 & 7385.293 & 7080 & -0.041 \\
\hline 20 & 98 & 104.4 & 0.068 & 8487.81 & 8924 & 0.051 \\
\hline 20 & 122 & 128.29 & 0.049 & 10763.56 & 1118 & 0.039 \\
\hline 20 & 163 & 157.64 & -0.034 & 15572.97 & 1397 & -0.102 \\
\hline 20 & 205 & 193.7 & -0.055 & 17509.67 & 1739 & -0.006 \\
\hline
\end{tabular}

History test shows a $5 \%$ relative error between variables $\mathrm{SV}$ and RV, showing a good fitness of reality, reliability and feasibility of the model. Therefore, the SD model constructed can be used in simulative project and policy simulation.

\section{SimUlative FORECAST}

Three methods of validity check (visual test, run test, history test) suggest guaranteed quality of model simulation which can be used in simulative project and policy simulation. Projection is made to year 2016 because longterm projection tends to be inaccurate with policy adjustment and changes thereof. Simulation tendency of some main variables output from VENSIM are shown in figure 4-6. 

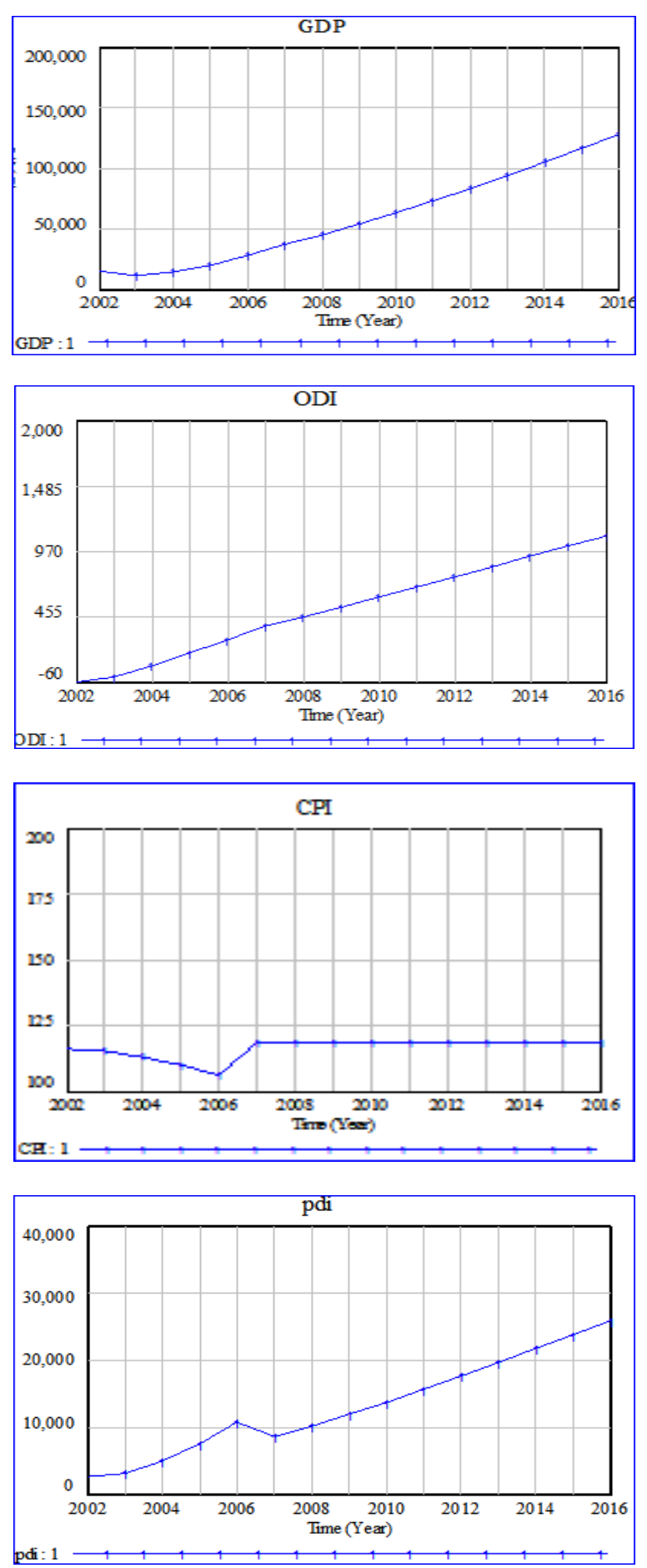

Figure 4. Simulation tendency of GDP, ODI, CPI \& PDI

It can be seen from figure 4 that, with the increasing tendency of GDP which indicates a prospective economic performance, China's ODI is also on the rise. With the increase of GDP, disposable income per capita is also increasing while CPI is relatively steady.
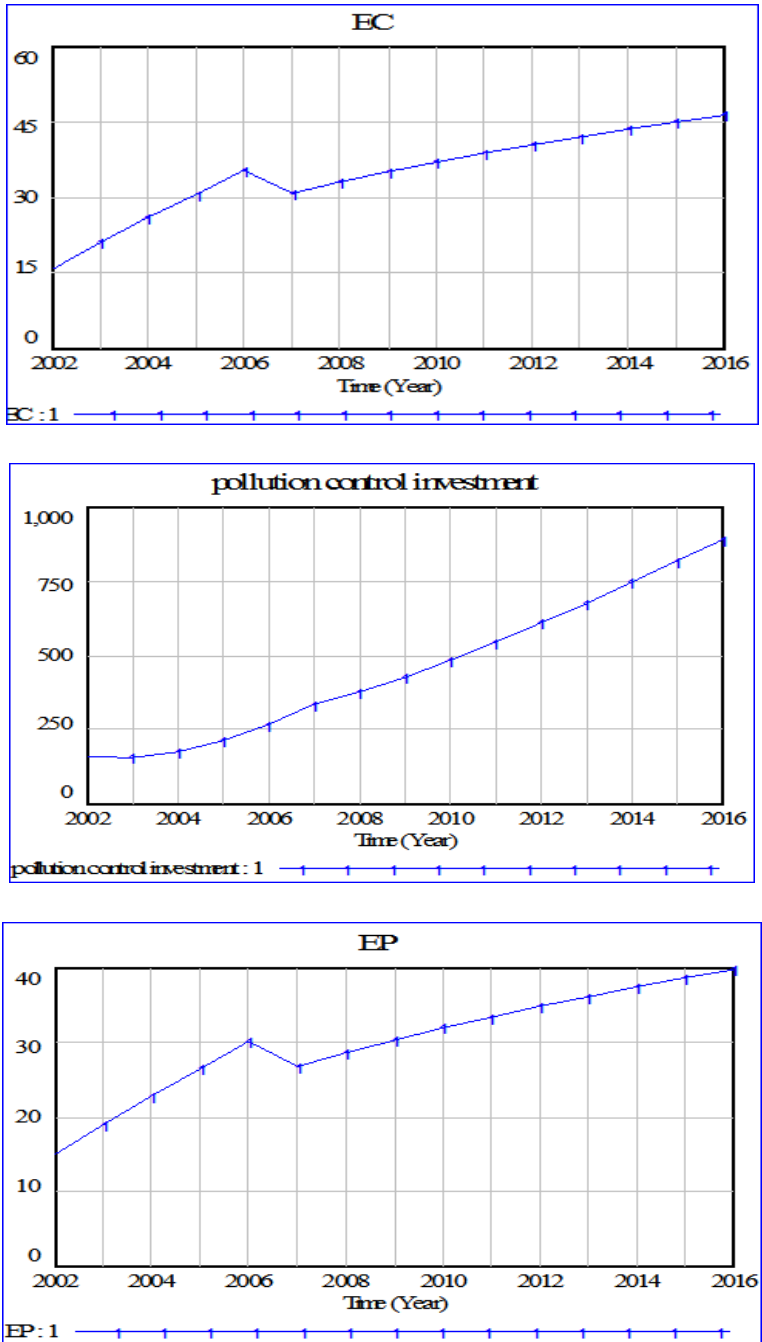

Figure 5. Simulation of energy consumption, energy production, and pollution management investment

It can be seen from figure 5 that China's energy consumption and pollution control investment are ever increasing, while growth rate of energy production is slowing down. China's energy consumption and energy production in 2002 are both close to 1.5 billion tons of standard coal. Nevertheless, China's energy consumption exceeds energy production since 2003, and by 2016 China's energy production is no more than 4 billion tons of standard coal while energy consumption reaches 4.5 billion tons of standard coal, which means a serious deficiency in China's energy supply. 

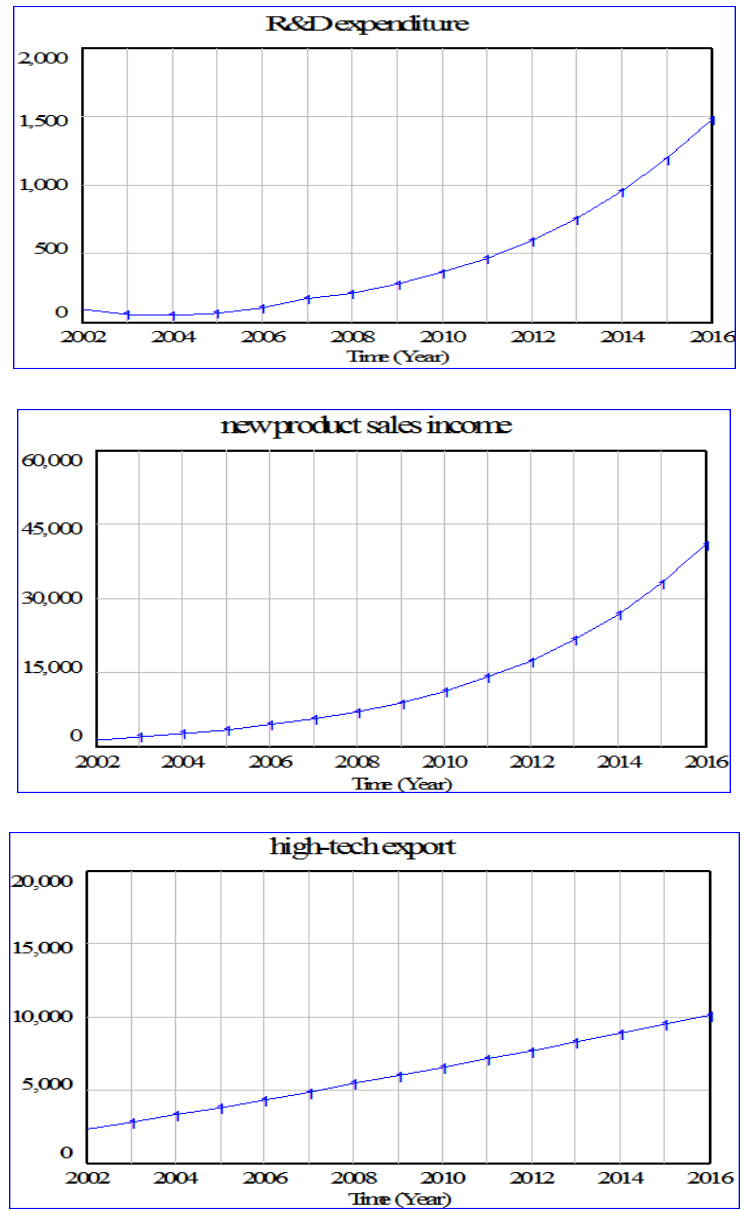

Figure 6. Simulation of R\&D, new product sales revenue, and high-tech export

It can be seen from figure 6 that new product sales revenue and high-tech export values increase with the increase of $R \& D$ expenditure.

\section{CONCLUSIONS}

Simulative forecast shows that China's energy consumption and pollution control investment are ever increasing, while growth rate of energy production is slowing down. China's energy consumption and energy production in 2002 are both close to 1.5 billion tons of standard coal. Nevertheless, China's energy consumption exceeds energy production since 2003, and by 2016 China's energy production is no more than 4 billion tons of standard coal while energy consumption reaches 4.5 billion tons of standard coal, which suggests a serious deficiency in China's energy supply and a necessity of importing energy to satisfy economic and social development. However, high level of imported energy might threaten to a certain degree China's energy safety.
Innovative capability should be further encouraged, be it fundamental technological breakthrough or average renovation, partial innovation or whole innovation, selfmotivated innovation or simply imitation, goal innovation or environment innovation, system innovation or institutional innovation. China is the biggest developing country as well as the biggest exporting country, while export lays a great demand for energy consumption. Long term export-led foreign trade has introduced low value added processing into China, which made many enterprises content with profits gained by low cost while pay little attention to technological innovation, HR cultivation, and brand innovation. Simulative forecast also shows that new product sales revenue and high-tech export values increase with the increase of R\&D expenditure. Promote policy-led organized innovation and stimulate technological innovation through system innovation, integrate them to form a real spur to robust economic development. Rely on technological innovation rather than government investment and export, target at improving citizens living standard and secure steady improvement in income. Change way of economic growth into coordinated development.

Government guidance is crucial to low carbon development, enterprises are the pivot of low carbon consumption, and public participation is the basis of low carbon society. Allocate more R\&D expenditure on research of energy-saving technology, on renewable resources development and environment protection. Lower dependence of energy import and optimize energy consumption structure, enhance efficiency in material use, and intensify pollution governance. Ensure quality of FDI at the outset, clamp down on high pollution enterprises.

\section{ACKNOWLEDGEMENTS}

This work was supported by the National Natural Science Foundation of China under Grant No. 71203079.

\section{REFERENCES}

[1] Fengxian Chen. China high FER: formation, influence and quantitative management [D]. 2012(4). In Chinese

[2] Tenglong Chen. Research of China's BOP twin surplus \& RMB exchange rate policy [D]. 2012(6). In Chinese

[3] Zhichuan Li. China FER increase and export-oriented economic structure — based on mercantilism study [D]. 2010-04. in Chinese

[4] Pei Guo, Shuxiao Zhang. FDI influence on China's carbon emission_ based on 2002-2010 panel data research [J]. 2013(3): 40-44 in Chinese

[5] Pei Guo, Shuxiao Zhang. Research of Relationship between China's carbon emission and FDI. 2012(8): 44-49. in Chinese.

[6] Pei Guo, Genghua Jiang, Shuxiao Zhang. FDI influence on China's carbon emission_— based on empirical study [J]. 2013(1): 47-52. In Chinese

[7] Zhi Zhou. Low carbon economy development path selection based on $S D$ [D]. 2011-03-17 .in Chinese

[8] Wei Lu. SD model construction and simulation of sustainable development of energy, environment, social and economic system [D]. 2010-05. in Chinese. 